\title{
Recent developments in the management of congenital cataract
}

\author{
Dominique Bremond-Gignac $^{1,2}$, Alejandra Daruich ${ }^{1,2}$, Matthieu P. Robert $^{1,3}$, Sophie Valleix ${ }^{2,4}$ \\ ${ }^{1}$ Ophthalmology Department, Necker-Enfants Malades Hospital, Paris University, Paris, France; ${ }^{2}$ INSERM UMRS 1138 , Team 17, From \\ Physiopathology of Ocular Diseases to Clinical Development, Université Sorbonne Paris Cité, Centre de Recherche des Cordeliers, Paris, France; \\ ${ }^{3}$ Borelli Centre, UMR 9010 CNRS-SSA-ENS Paris Saclay-Paris University, Paris, France; ${ }^{4}$ Molecular Genetics, University Hospital Necker-Enfants \\ Malades, APHP, OPHTARA Center, Paris, France \\ Contributions: (I) Conception and design: D Bremond-Gignac; (II) Administrative support: None; (III) Provision of study materials or patients: None; \\ (IV) Collection and assembly of data: D Bremond-Gignac, A Daruich, S Valleix; (V) Data analysis and interpretation: All authors; (VI) Manuscript \\ writing: All authors; (VII) Final approval of manuscript: All authors. \\ Correspondence to: Professor Dominique Bremond-Gignac. Ophthalmology Department, University Hospital Necker-Enfants Malades, 149, rue de \\ Sèvres, 75015 Paris, France. Email: dominique.bremond@aphp.fr.
}

\begin{abstract}
Congenital cataract is a rare eye disease, one of the leading treatable causes of low vision in children worldwide. Hereditary cataracts can be divided in syndromic and non-syndromic cataracts. Early diagnosis in congenital cataracts is key to reach good visual function. Current surgical techniques, that combine microincision cataract extraction and primary intraocular lens (IOL) implantation, have improved childhood cataract outcome. Complications include posterior capsule opacification (PCO), aphakic or pseudophakic glaucoma, uveitis, pupil displacement and IOL decentration. A recent study using a modified Delphi approach identified areas of consensus and disagreement in the management of pediatric cataract. A consensus or near consensus was achieved for $79 \%$ of the questions, however $21 \%$ of the questions remained controversial, as for IOL implantation strategy. Congenital cataracts show a highly variable phenotype and genotype, and can be related to different mutations, genetic variance, and other risk factors. Congenital cataracts can be associated with other ocular developmental abnormalities, including microphthalmia, microcornea, or aniridia and with systemic findings. Next-generation sequencing (NGS) and forthcoming new ultra-high-throughput sequencing represent excellent tools to investigate the genetic causes of congenital cataracts. A better recognition of different clinical presentations and underlying etiologies of congenital cataracts may lead to the development of new approaches to improve visual outcome after cataract surgery and promote early detection of systemic associated syndromes.
\end{abstract}

Keywords: Congenital cataract; Delphi study; cataract surgery; molecular genetics; systemic syndromes

Submitted Apr 01, 2020. Accepted for publication Jul 19, 2020.

doi: $10.21037 / \mathrm{atm}-20-3033$

View this article at: http://dx.doi.org/10.21037/atm-20-3033

\section{Introduction}

Congenital cataract is a rare eye disease, with a variable prevalence of 0.6-9.3/10,000 live births (1). It remains one of the leading causes of visual loss in children worldwide. Congenital cataract is considered a preventable cause of blindness. However, a late diagnosis and treatment lead to irreversible deprivation amblyopia and permanent severe visual impairment or blindness. Cataract can be defined as a loss of transparence of the lens, occasionally leading to a change in its refractive index. The term cataract comes from the Greek katarraktes and then transformed in the Latin word cataracta. However, the term cataract was first used in an ophthalmic sense with the Latin cataracta in the 5th century CE (2). Congenital or neonatal cataract is defined as a cataract observed within the first year of life. The term juvenile cataract is used when onset occurs within the first decade of life. Congenital cataracts have numerous causes, many of them remaining unknown (3). They are usually 
associated with an alteration of the lens micro-architecture and result from abnormal lens development during embryonic to postnatal stages, due to various disruptive factors, including genes mutations. Most childhood cataracts are isolated, while some are associated to other ocular developmental anomalies, such as microphthalmia, aniridia or microcornea, and/or systemic disorders. Inherited congenital cataracts show all types of inheritance patterns in a syndromic and non-syndromic form. Syndromic cataract should be suspected when systemic findings are present among the clinical symptomatology. An early screening of syndromic cataract allows a better management of systemic associated anomalies.

Recent innovations including DNA sequencing, high resolution imaging and new tools in pediatric surgery have improved the screening, detection and management of congenital cataracts $(3,4)$. The timing of cataract surgery is one of the main factor influencing the visual outcome (3). However, despite early surgery and intense amblyopia rehabilitation, children may still develop several complications, including glaucoma and low vision (5).

\section{Current clinical practice in congenital cataract}

The main function of crystalline lens is its role in the refractive vision. Congenital cataracts lead to lens opacity, but also impair lens growth, eyeball axial length and refractive properties, all leading to vision loss.

\section{Epidemiology and classification}

A meta-analysis calculated the prevalence of congenital cataract, based on 8,302,708 children from 17 population studies from different continents between 1959 and 2010 . The overall pooled prevalence was 4.24 cases per 10,000 children (6).

Congenital cataracts show a variable degree of severity from minimal to dense opacity, independently of the associated mutation that can differ or be identical for the same degree of opacity. Congenital cataracts are usually classified morphologically as total, anterior polar, nuclear (Figure 1A), posterior polar, posterior subcapsular, lamellar, pulverulent (Figure 1B), zonular, sutural, cerulean, cartwheel (Figure 1C) coraliform or polymorphic (7).

\section{Associated ocular anomalies and syndromic cataracts}

Congenital cataracts can occur either in isolation, or in association with other ocular abnormalities, such as microcornea, coloboma, anterior segment defects, microphthalmia, aniridia (Figure 1C), persistent fetal vasculature (8) (Figure 1D) and retinal disorders, such as retinal dystrophies. Furthermore, congenital cataract may be associated with systemic syndromes and multisystem genetic disorders, requiring a pediatric work-up. Over 200 syndromes with pediatric cataract have been reported (9) and should be investigated. Many chromosomal disorders, including Down syndrome (Trisomy 21), Trisomy 18, cridu-chat syndrome (5p deletion), and 22q11.2 deletion syndrome (9), can be associated with pediatric cataracts.

\section{Cataract diagnosis and management}

Early diagnostic remains essential in congenital cataract, since the timing of surgery is one of the main factor influencing visual outcome (3). Early screening for congenital cataracts has been developed worldwide to optimize management of affected children. Prenatal imaging diagnosis by ultrasound and, if needed, genetic testing, can be performed for fetus at early gestational stages (10-12). For visually-significant cataracts leading to a high risk of amblyopia, surgical intervention is recommended at 6 weeks of age for unilateral cases and before 8 weeks of age for bilateral ones $(13,14)$. Microincision cataract aspiration combined with posterior capsulotomy, anterior vitrectomy and primary intraocular lens (IOL) implantation is now recognized as the optimal surgical option for the management of a large part of pediatric cataracts (15). Posterior capsulotomy and anterior vitrectomy are particularly important to reduce posterior capsule opacification (PCO) and recommended until 4-8 years, a presumed cooperative age for $\mathrm{Nd}$ : YAG procedure. Primary IOL implantation is usually performed in children older than 2 years of age. However, IOL implantation in children younger than 2 years of age remains a matter of controversy, despite the increasing evidence of safety for the procedure (16). IOL implantation before 7 months of age is considered at high risk of severe postoperative complications, as inflammation, PCO (Figure 1E) and glaucoma, particularly in bilateral cases (17-19). However, some authors have suggested implantation as early as 3 months for unilateral cataracts and 7 months for bilateral ones (20). A recent meta-analysis showed that primary IOL implantation in children younger than 2 years resulted in better visual acuity than aphakia and contact lens wearing, but increased incidence of PCO. The prevalence of 

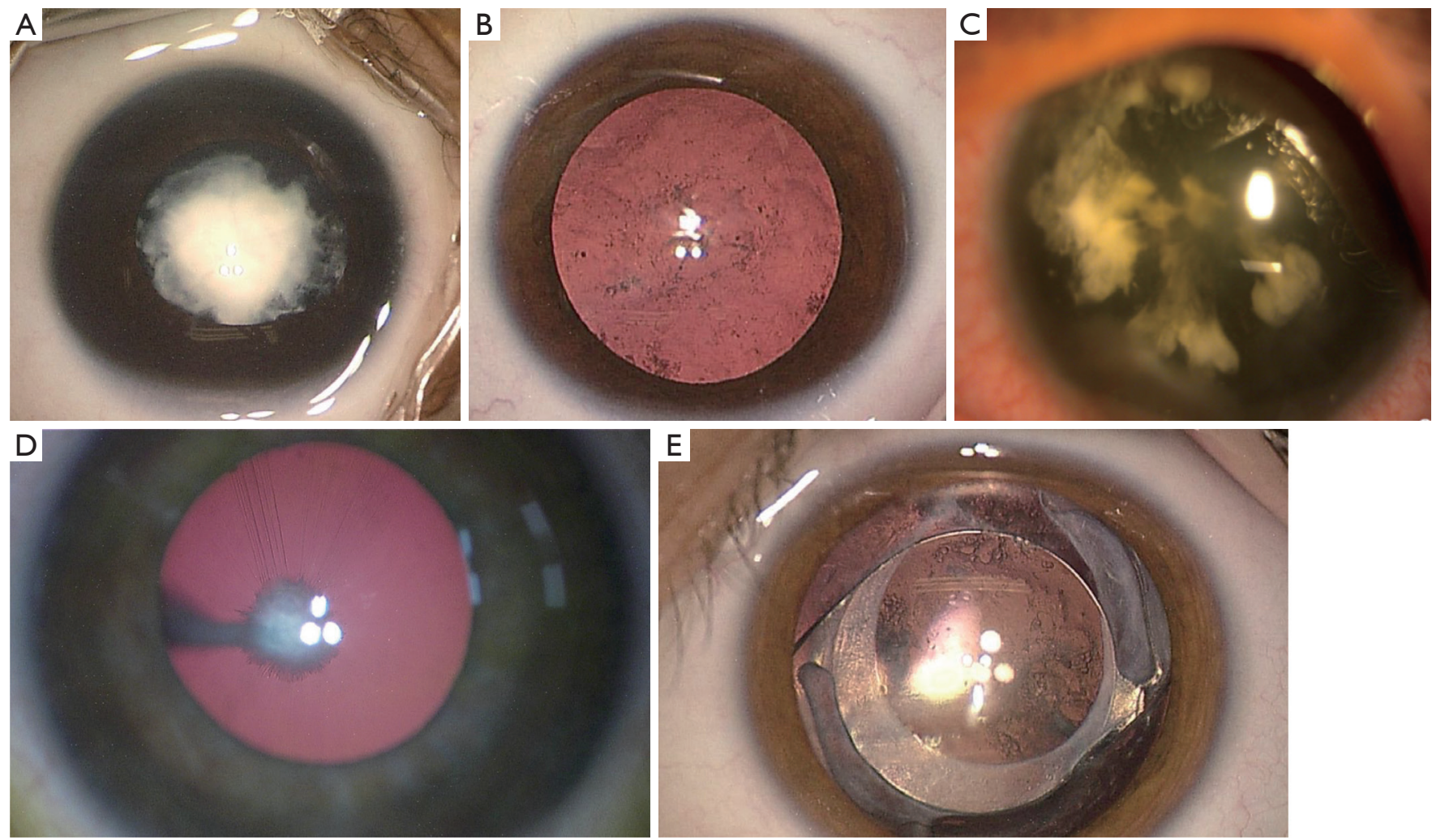

Figure 1 Congenital cataract morphology and main postoperative complication of congenital cataract surgery. (A) White nuclear congenital cataract. (B) Pulverulent congenital cataract. (C) cart-wheel congenital cataract in an aniridia patient. (D) Congenital cataract associated with persistent fetal vasculature. (E) Posterior capsule opacification in congenital cataract even after posterior capsulorhexis.

glaucoma and strabismus was similar between the groups. Authors suggested that cataract surgery in children younger than 2 years should include primary IOL implantation, associated with optic capture or bag-in-the-lens IOL implantation techniques to reduce PCO incidence (16). However, when cataract is associated with others ocular conditions as microphthalmia, IOL implantation should be delayed (21). Foldable hydrophobic acrylic is one of most used IOL material, since it remains stable and leads to less severe inflammation and PCO (22). Hydrophobic acrylic IOLs have been associated with a higher incidence of glistening that might impair visual performance, after cataract extraction in adults (23). New glisteningfree material seems then suitable (24). Children have a higher degree of visual plasticity than adults (25) but the impact of glistening on visual quality has not been further investigated. Additionally, there is no study evaluating glistening-free IOLs in the pediatric population. Because of the continuous axial growth in pediatric patients,
IOL power is under-corrected, based on patient age. The best formula for IOL power calculation remains unclear. The report of Infant Aphakia Treatment Study Group recommended Holladay 1 and SRK/T formulae for pediatric eyes (19). However, less than $50 \%$ of the children were within $1.00 \mathrm{D}$ of target refraction with refractive errors ranging from +5.00 to $-19.00 \mathrm{D}$ at 5 years (26). The inability to predict axial elongation in pediatric eyes could induce surgeons to prefer aphakia and contact lens wearing for surgeries performed before 6 months of age. Common complications of childhood cataract surgery include PCO (more precisely, Elschnig pearls proliferation and secondary membranes), despite posterior capsulorhexis (Figure 1E), aphakic or pseudophakic glaucoma, uveitis, pupil displacement and IOL decentration (5). Long-term visual outcome at 10 years and complication rates at 5 years seems similar after cataract extraction with or without primary IOL implantation $(27,28)$. 


\section{Page 4 of 9}

\section{Delphi study process in pediatric cataract management}

Management options for cataract in children remain challenging since only few randomized clinical trials have been undertaken. Over the last years, the Delphi process has gained noteworthiness to investigate the subject. The Delphi approach is a method used to obtain consensus among experts in controversial areas. Using a modified Delphi approach, areas of consensus and disagreement in the management of pediatric cataract were recently identified (29). Pediatric cataract experts formed a committee to answer questionnaires in rounds and after each round a facilitator provided an anonymous summary of the experts' opinions and the supportive arguments. Experts were encouraged to revise their earlier answers considering those of other members of their panel, thus decreasing the range of the answers, which ultimately could converge towards a consensus. Sixteen of 22 pediatric cataract surgeons agreed to participate. Four rounds were conducted electronically. Questions without consensus from the first three rounds ( $\mathrm{n}=52$ questions) were discussed by 10 or 11 experts in a 2-day face-to-face meeting. While consensus was achieved for 85/108 questions considered, there still remained 23 important surgical questions for which a consensus could not be reached. Although there was consensus on when performed surgery for a visually significant cataract (4-6 weeks of age for unilateral cataract and before 8 weeks of age for bilateral cataract), there was no agreement concerning the minimum age for primary IOL implantation for unilateral or bilateral cataract, the formula to calculate IOL power or the type of hydrophobic IOL, single or three piece, that should be used. However, multifocal or toric lenses were not recommended in the management of pediatric cataract. Regarding the timing of secondary implantation most experts agreed with implantation at 4-8 years in cases where contact lenses were tolerated and at the earliest (even before 1 year of age) in cases without contact lenses tolerance. Iris claw was the recommended IOL in the absence of capsular support. Some important questions as whether intracameral antibiotics should be used at the end of the surgery remained without consensus. Silicone contact lens was the preferred material for aphakic children younger than 3 years of age but there was no agreement concerning the preferred material for older children. Even if some questions remained unanswered, the Delphi study allowed to harmonize clinical practice and contributed to guideline the management of congenital cataract worldwide.
Bremond-Gignac et al. Recent developments in congenital cataract

\section{Molecular genetics in congenital cataracts}

Mutations in over 300 genes associated with cataracts have been reported and the complete list of all these genes and loci is provided in the Cat-Map database (http://cat-map. wustl.edu/) (30). The scope of this section is to only briefly describe the genetic picture of congenital cataracts with its general characteristics, and for more details, recent excellent reviews on the genetic landscape of congenital cataracts are recommended with their corresponding references herein (9,31-33).

\section{Genotype and phenotype heterogenicity of congenital cataracts}

The genes involved in congenital cataracts can be separated in four major sub-groups, including genes consistently involved in syndromic congenital cataract; genes involved in syndromic congenital cataract, which can also cause isolated congenital cataract; genes responsible for congenital cataract with other ocular abnormalities; and finally, genes associated with non-syndromic congenital cataract with no other associated eye defects (32). The phenotype of congenital cataracts associated with the different known genes is highly complex, including a large variety of morphologic configurations and variable severity (9). The level of phenotypic heterogeneity is further complicated by the presence of additional ocular abnormalities, including microcornea, microphthalmia, aniridia, anterior chamber abnormalities, myopia, and retinal or vitreous degeneration, depending on the mutation type and/or the causative gene (34). The molecular basis for this great clinical heterogeneity is unclear and it is not well correlated with the genotype, since different mutations, or even a same mutation, in a single gene, can exhibit pleiotropic effects, or conversely more than one genotype can produce similar clinical phenotype. Remarkably, an additional level of complexity in congenital cataract results from the very high proportion of sporadic cases, and the fact that only $18 \%$ of pediatric patients have a positive family history (35). It has been shown that the vast majority of these sporadic cases results in fact from germline or postzygotic de novo mutations in genes with autosomal dominant transmission of the disease.

\section{Gene mutations associated to non-syndromic congenital cataracts}

To date, $30-40 \%$ of congenital cataracts are thought 
to have a genetic cause, and mutations in more than 35 genes have significantly been associated with nonsyndromic congenital cataracts with or without additional eye abnormalities $(9,31)$. Among cataract families which a known mutant gene, about $45 \%$ show mutations in lens crystallins, $16 \%$ in connexins, about $12 \%$ in growth or transcription factors, $5 \%$ in protein degradation apparatus, $5 \%$ in membrane proteins, $5 \%$ in intermediate filament proteins, and about $8 \%$ in other functionally divergent genes including those for lipid metabolism (30,31,36-39). Indeed, a major breakthrough in the understanding of the mechanism of cataract formation has come from the recent genetic discovery by whole exome sequencing (WES) that mutations in the gene encoding the enzyme lanosterol synthase (LSS) are responsible for autosomal recessive congenital cataracts (40). This finding has conducted to the application of eye drops containing lanosterol to reverse protein aggregation in dogs, adding new major scientific insight into cataractogenesis. Congenital cataracts may be inherited as autosomal recessive, $\mathrm{X}$-linked recessive, or autosomal dominant, the latter being the commonest mode. However, both patterns of dominant and recessive inheritance have been described for some genes, notably FOXE3, PITX3, HSF4, and at least three crystalline genes (CRYBA1, CRYBB1, CRYBB3), for which dominant and recessive alleles represent distinct types of mutations (9). The crystalline proteins represent more than $90 \%$ of the total soluble protein in lens, and consequently crystallin genes are the largest known gene family linked with congenital cataract (41). More than 60 mutations in seven crystallin genes (CRYAA, CRYAB, CRYBB1, CRYBB2, $C R Y B B 3, C R Y G C$, and $C R Y G D$ ) have been reported to date in patients with pediatric cataracts and these mutations are related with to various cataract phenotypes. Crystallins are subdivided in 3 major classes, alpha-crystallins being the major lens protein where they exert a structural role and act as a molecular chaperone preventing self-association and abnormal aggregation of a large number of partially folded proteins $(41,42)$. Crystallins are highly conserved proteins, deriving from an ancestral single protein domain called "the Greek key", a structural motif essential to ensure the transparency and the refractive index of the lens. Most of the pathogenic mutations in the crystalline genes disrupted the Greek key domains of the crystalline proteins (41). Mutations in the GFA8 and GFA3 genes, coding connexin 50 and connexin 46, respectively, essential to maintain a network of gap junction channels for transport of ions and low molecular weight biomolecules between lens fiber cells, cause congenital cataract with various phenotypes (43). To date, at least 50 and 38 mutations in $G \mathcal{F A 8}$ and $G \mathcal{F} A 3$ have been reported, with $G \mathcal{A} A 8$ mutations associated in $50 \%$ of cases with microcornea or microphthalmia, reflecting also its role in fiber cell growth (44). Only 5 mutations and 7 mutations, with both dominant and recessive patterns, have been reported in the BSFP1 and BSFP2 genes, coding intermediate filament proteins forming beaded filaments specific to the lens. Mutations in the transcription factor genes FOXE3, PAX6, MAF, HSF4, and PITX3, all playing key functions in eye development, cause cataracts that can be associated with various eye congenital defects including anterior segment mesenchymal dysgenesis (ASMD), microcornea, microphthalmia, iris coloboma or defects in non-ocular tissues (45). Mutations in PITX3 cause congenital cataract and ASMD with autosomal dominance inheritance (46). Majority of PITX3 mutations identified so far are in exon 4, coding the homeodomain, except the missense PITX3 mutation (p.Ser13Asp) reported by Semina et al. $(46,47)$. Recessive mutations in the FOXE3 gene are associated with microphthalmia, aphakia, glaucoma, and sclerocornea, whereas heterozygous dominant mutations, often resulting in erroneous protein extension, have been associated with congenital cataract with or without ASMD (48-50).

\section{Gene mutations associated to syndromic congenital cataracts}

MAF gene mutations have been reported in patients presenting with different ocular anomalies including congenital cataract. MAF mutations have been also associated with Aymé-Gripp syndrome, which combines congenital cataract, flat facial features resembling Down syndrome, brachycephaly, seizures, intellectual disability and deafness. $P A X 6$-associated cataract may present as an autosomal-dominant cataract with congenital nystagmus (51). Identification of a PAX6 mutation in a family with cataract should lead to a different management of these patients including regular screening for PAX6associated complications, such as limbal insufficiency, glaucoma, and foveal hypoplasia, that could all impact longterm visual function (52). Additionally, several genes that usually cause $\mathrm{X}$-linked syndromic cataracts, such as $\mathrm{NHS}$, $O C R L$, or BCOR, associated with Nance-Horan syndrome, Lowe oculocerebrorenal syndrome, and oculo-facio-cardiodental (OFCD) syndrome respectively, may initially present as isolated congenital cataracts. The associated systemic 
features may develop with time, and the full spectrum of clinical features accompanying these $\mathrm{X}$-linked syndromic cataracts often becomes obvious later in childhood, raising the possibility of undiagnosed female carriers, who are at risk of having more than one affected male offspring. Therefore, the correct molecular diagnosis is of utmost importance in these $\mathrm{X}$-linked cases to revision of diagnoses, accurate recurrence risk counseling with impact on management of families having in fact a multisystemic disease with more severe prognosis. Since the introduction of Next Generation Sequencing, numerous cases of Lowe and OFCD syndromes initially presenting with isolated congenital cataracts, have been recognized. Lowe syndrome, a rare $\mathrm{X}$-linked recessive disorder, that usually combined congenital cataract, renal selective proximal tubular dysfunction and intellectual disability, but the first typical diagnostic clues apparent at birth are a dense congenital cataract with muscular hypotonia. In this syndrome, the cataracts develop early in embryogenesis due to degeneration of the primary posterior lens fibers, detectable on prenatal ultrasound images. Other ocular anomalies are also found in Lowe Syndrome. Half of patients develop severe glaucoma and buphthalmos requiring surgical management. About $25 \%$ of patients could present with corneal scarring and keloids in the absence of trauma. Due to the risk of corneal keloid formation contact lenses use is not recommended (53). Conversely, OFCD syndrome an $\mathrm{X}$-linked dominant disorder, lead to male lethality, while affected females may present congenital cataracts, isolated or associated with other ocular or extraocular findings as unilateral/bilateral microphthalmia, facial dysmorphism, cardiac defects, or dental anomalies (54). OFCD syndrome is caused by a variety of truncating $B C O R$ variants, predicted to result in nonsense mediated mRNA decay (55-58).

\section{Next-generation sequencing (NGS) methods}

To date, we still do not have a definitive comprehensive landscape on the molecular basis of congenital cataracts, because the vast majority of genetic studies have been conducted through a phenotype-based approach that includes phenotypic characterization of the cataract followed by individual exon-by-exon Sanger sequencing of one or more suspected known cataract-associated genes. This sequencing approach is unable to identify all potential molecular defects in a gene, such as copy-number variations (CNVs). It is still not known whether the phenotypic variability observed in cataract might result from a complex inheritance of mutations in more than one known cataract gene or as-yet-unknown loci that could interact with each other, affecting the genetic cataract trait by modifying the severity, range of the phenotype, or the occurrence of additional ocular abnormalities. Today, NGS methods are becoming increasingly accessible in the clinical laboratory setting and supplant conventional exon-based screening approaches, providing an accurate high-throughput genotype-based approach to molecular diagnosis of genetic diseases. The development of a massively parallel sequencing method applied to genes involved in congenital cataracts has the potential to reliably identify all types of genetic variations, including CNVs, and can increase substantially the diagnostic yield. Such high-yield mutation detection method in different large cohorts of patients would help to provide a molecular diagnosis in the significant proportion of cataract cases/families for whom existing diagnostic methods were not conclusive, and would help to better understand phenotype-genotype correlation as well as to explore the possibility of genetic interactions between different loci. NGS with deep sequence coverage might improve the detection of de novo mutations and the accurate quantification of the level of mosaicism that would be undetectable by conventional Sanger sequencing. This would provide better insights into the spectrum of de novo genetic alterations in congenital cataracts. For the remaining unsolved cases, other NGS strategies will be used by applying untargeted WES in order to search for novel genes responsible for congenital cataracts. Improved knowledge of the functional consequences of diseasemutations allows for the possibility of new therapeutic options in the future.

\section{Conclusions and future perspectives}

A better recognition of different clinical presentations and underlying etiologies of congenital cataracts may lead to the development of new approaches to reduce childhood blindness due to congenital cataract and promote early detection of systemic associated syndromes.

In summary, early diagnosis by effective screening, handheld innovative imaging targeted for children, advances in DNA sequencing technologies and adapted genetic counseling have significantly improve understanding of underlying etiologies and childhood visual outcome due to congenital cataracts. Genomic medicine is revolutionizing the care pathway. NGS, and forthcoming new ultra-highthroughput sequencing, are excellent tools for analyzing 
inherited cataracts. Improved knowledge of the functional consequences of cataract disease-mutations allows for the possibility of innovative therapeutic options in the future.

\section{Acknowledgments}

Funding: None.

\section{Footnote}

Provenance and Peer Review: This article was commissioned by the Guest Editor (Dr. Andrzej Grzybowski) for the series "Recent developments in cataract surgery" published in Annals of Translational Medicine. The article was sent for external peer review organized by the Guest Editor and the editorial office.

Conflicts of Interest: All authors have completed the ICMJE uniform disclosure form (available at http:// dx.doi.org/10.21037/atm-20-3033). The series "Recent developments in cataract surgery" was commissioned by the editorial office without any funding or sponsorship. The authors have no other conflicts of interest to declare.

Ethical Statement: The authors are accountable for all aspects of the work in ensuring that questions related to the accuracy or integrity of any part of the work are appropriately investigated and resolved.

Open Access Statement: This is an Open Access article distributed in accordance with the Creative Commons Attribution-NonCommercial-NoDerivs 4.0 International License (CC BY-NC-ND 4.0), which permits the noncommercial replication and distribution of the article with the strict proviso that no changes or edits are made and the original work is properly cited (including links to both the formal publication through the relevant DOI and the license). See: https://creativecommons.org/licenses/by-nc-nd/4.0/.

\section{References}

1. Sheeladevi S, Lawrenson JG, Fielder AR, et al. Global prevalence of childhood cataract: a systematic review. Eye (Lond) 2016;30:1160-9.

2. Leffler CT. The history of Glaucoma. In: The history of Glaucoma. Wayenborgh Publishing; 2020. (The history of ophthalmology The Monographs; vol. 15).

3. Chan WH, Biswas S, Ashworth JL, et al. Congenital and infantile cataract: aetiology and management. Eur J Pediatr 2012;171:625-30.

4. Gillespie RL, Urquhart J, Anderson B, et al. Nextgeneration Sequencing in the Diagnosis of Metabolic Disease Marked by Pediatric Cataract. Ophthalmology 2016;123:217-20.

5. Gasper C, Trivedi RH, Wilson ME. Complications of Pediatric Cataract Surgery. Dev Ophthalmol 2016;57:69-84.

6. Wu ZHY, Lai RYK, Yip YWY, et al. Improvement in multifocal electroretinography after half-dose verteporfin photodynamic therapy for central serous chorioretinopathy: a randomized placebo-controlled trial. Retina (Philadelphia, Pa) 2011;31:1378-86.

7. Hejtmancik JF. Congenital cataracts and their molecular genetics. Semin Cell Dev Biol 2008;19:134-49.

8. Shiels A, Hejtmancik JF. Mutations and mechanisms in congenital and age-related cataracts. Exp Eye Res 2017;156:95-102.

9. Reis LM, Semina EV. Genetic landscape of isolated pediatric cataracts: extreme heterogeneity and variable inheritance patterns within genes. Hum Genet 2019;138:847-63.

10. Drought A, Wimalasundera R, Holder S. Ultrasound diagnosis of bilateral cataracts in a fetus with possible cerebro-ocular congential muscular dystrophy during the routine second trimester anomaly scan. Ultrasound 2015;23:181-5.

11. Brémond-Gignac D, Copin H, Elmaleh M, et al. Fetal ocular anomalies: the advantages of prenatal magnetic resonance imaging. J Fr Ophtalmol 2010;33:350-4.

12. Ashwal E, Achiron A, Gilboa Y, et al. Prenatal Ultrasonographic Diagnosis of Cataract: In Utero Manifestations of Cryptic Disease. Ultraschall Med 2018;39:213-8.

13. Kim DH, Kim JH, Kim SJ, et al. Long-term results of bilateral congenital cataract treated with early cataract surgery, aphakic glasses and secondary IOL implantation. Acta Ophthalmol 2012;90:231-6.

14. Lambert SR, Lynn MJ, Reeves R, et al. Is there a latent period for the surgical treatment of children with dense bilateral congenital cataracts? J AAPOS 2006;10:30-6.

15. Wang M, Xiao W. Congenital Cataract: Progress in Surgical Treatment and Postoperative Recovery of Visual Function. Eye Sci 2015;30:38-47.

16. Chen J, Chen Y, Zhong Y, et al. Comparison of visual acuity and complications between primary IOL implantation and aphakia in patients with congenital cataract younger than 2 years: a meta-analysis. J Cataract 
Refract Surg 2020;46:465-73.

17. Vasavada AR, Vasavada V. Current Status of IOL implantation in pediatric eyes: an update. Expert Rev Med Devices 2017. [Epub ahead of print].

18. Solebo AL, Russell-Eggitt I, Cumberland PM, et al. Risks and outcomes associated with primary intraocular lens implantation in children under 2 years of age: the IoLunder2 cohort study. Br J Ophthalmol 2015;99:1471-6.

19. Lambert SR, Lynn MJ, Hartmann EE, et al. Comparison of contact lens and intraocular lens correction of monocular aphakia during infancy: a randomized clinical trial of HOTV optotype acuity at age 4.5 years and clinical findings at age 5 years. JAMA Ophthalmol 2014;132:676-82.

20. Kumar P, Lambert SR. Evaluating the evidence for and against the use of IOLs in Infants and Young Children. Expert Rev Med Devices 2016;13:381-9.

21. Praveen MR, Vasavada AR, Shah SK, et al. Long-term postoperative outcomes after bilateral congenital cataract surgery in eyes with microphthalmos. J Cataract Refract Surg 2015;41:1910-8.

22. Wilson ME, Trivedi RH, Buckley EG, et al. ASCRS white paper. Hydrophobic acrylic intraocular lenses in children. J Cataract Refract Surg 2007;33:1966-73.

23. Grzybowski A, Kanclerz P, Beiko GHH. IOLs glistenings and quality of vision. Graefes Arch Clin Exp Ophthalmol 2019;257:2795-6.

24. Werner L, Thatthamla I, Ong M, et al. Evaluation of clarity characteristics in a new hydrophobic acrylic IOL in comparison to commercially available IOLs. J Cataract Refract Surg 2019;45:1490-7.

25. Kiorpes L. The Puzzle of Visual Development: Behavior and Neural Limits. J Neurosci 2016;36:11384-93.

26. Nischal KK. State of the Art in Pediatric Cataract Surgery. Dev Ophthalmol 2016;57:15-28.

27. Lambert SR, Cotsonis G, DuBois L, et al. Long-term Effect of Intraocular Lens vs Contact Lens Correction on Visual Acuity After Cataract Surgery During Infancy: A Randomized Clinical Trial. JAMA Ophthalmol 2020;138:365-72.

28. Tadros D, Trivedi RH, Wilson ME. Primary versus secondary IOL implantation following removal of infantile unilateral congenital cataract: outcomes after at least 5 years. J AAPOS 2016;20:25-9.

29. Serafino M, Trivedi RH, Levin AV, et al. Use of the Delphi process in paediatric cataract management. $\mathrm{Br} \mathrm{J}$ Ophthalmol 2016;100:611-5.

30. Shiels A, Bennett TM, Hejtmancik JF. Cat-Map: putting cataract on the map. Mol Vis 2010;16:2007-15.

31. Shiels A, Hejtmancik JF. Biology of Inherited Cataracts and Opportunities for Treatment. Annu Rev Vis Sci 2019;5:123-49.

32. Messina-Baas O, Cuevas-Covarrubias SA. Inherited Congenital Cataract: A Guide to Suspect the Genetic Etiology in the Cataract Genesis. Mol Syndromol 2017;8:58-78.

33. Patel N, Anand D, Monies D, et al. Novel phenotypes and loci identified through clinical genomics approaches to pediatric cataract. Hum Genet 2017;136:205-25.

34. Li J, Xia CH, Wang E, et al. Screening, genetics, risk factors, and treatment of neonatal cataracts. Birth Defects Res 2017;109:734-43.

35. Wirth MG, Russell-Eggitt IM, Craig JE, et al. Aetiology of congenital and paediatric cataract in an Australian population. Br J Ophthalmol 2002;86:782-6.

36. Zhai Y, Li J, Yu W, et al. Targeted Exome Sequencing of Congenital Cataracts Related Genes: Broadening the Mutation Spectrum and Genotype-Phenotype Correlations in 27 Chinese Han Families. Sci Rep 2017;7:1219.

37. Ma AS, Grigg JR, Ho G, et al. Sporadic and Familial Congenital Cataracts: Mutational Spectrum and New Diagnoses Using Next-Generation Sequencing. Hum Mutat 2016;37:371-84.

38. Li D, Wang S, Ye H, et al. Distribution of gene mutations in sporadic congenital cataract in a Han Chinese population. Mol Vis 2016;22:589-98.

39. Gillespie RL, O'Sullivan J, Ashworth J, et al. Personalized diagnosis and management of congenital cataract by nextgeneration sequencing. Ophthalmology 2014;121:212437.e1-2.

40. Zhao L, Chen XJ, Zhu J, et al. Lanosterol reverses protein aggregation in cataracts. Nature 2015;523:607-11.

41. Ecroyd H, Carver JA. Crystallin proteins and amyloid fibrils. Cell Mol Life Sci 2009;66:62-81.

42. Andley UP. Crystallins in the eye: Function and pathology. Prog Retin Eye Res 2007;26:78-98.

43. Beyer EC, Ebihara L, Berthoud VM. Connexin mutants and cataracts. Front Pharmacol 2013;4:43.

44. Shiels A, Mackay D, Ionides A, et al. A missense mutation in the human connexin50 gene (GJA8) underlies autosomal dominant "zonular pulverulent" cataract, on chromosome 1q. Am J Hum Genet 1998;62:526-32.

45. Anand D, Agrawal SA, Slavotinek A, et al. Mutation update of transcription factor genes FOXE3, HSF4, MAF, and PITX3 causing cataracts and other developmental ocular defects. Hum Mutat 2018;39:471-94. 
46. Semina EV, Ferrell RE, Mintz-Hittner HA, et al. A novel homeobox gene PITX3 is mutated in families with autosomal-dominant cataracts and ASMD. Nat Genet 1998;19:167-70.

47. Verdin H, Sorokina EA, Meire F, et al. Novel and recurrent PITX3 mutations in Belgian families with autosomal dominant congenital cataract and anterior segment dysgenesis have similar phenotypic and functional characteristics. Orphanet J Rare Dis 2014;9:26.

48. Semina EV, Brownell I, Mintz-Hittner HA, et al. Mutations in the human forkhead transcription factor FOXE3 associated with anterior segment ocular dysgenesis and cataracts. Hum Mol Genet 2001;10:231-6.

49. Valleix S, Niel F, Nedelec B, et al. Homozygous nonsense mutation in the FOXE3 gene as a cause of congenital primary aphakia in humans. Am J Hum Genet 2006;79:358-64.

50. Brémond-Gignac D, Bitoun P, Reis LM, et al. Identification of dominant FOXE3 and PAX6 mutations in patients with congenital cataract and aniridia. Mol Vis 2010;16:1705-11.

51. Bremond-Gignac D. Congenital aniridia in children. Rev Prat 2019;69:67-70.

52. Lee H, Meyers K, Lanigan B, et al. Complications and

Cite this article as: Bremond-Gignac D, Daruich A, Robert MP, Valleix S. Recent developments in the management of congenital cataract. Ann Transl Med 2020;8(22):1545. doi: 10.21037/atm-20-3033 visual prognosis in children with aniridia. J Pediatr Ophthalmol Strabismus. 2010;47:205-10; quiz 211-2.

53. Lewis RA, Nussbaum RL, Brewer ED. Lowe Syndrome. In: Adam MP, Ardinger HH, Pagon RA, et al. editors. GeneReviews®. Seattle (WA): University of Washington, Seattle, 1993.

54. Zhou Y, Wojcik A, Sanders VR, et al. Ocular findings in a patient with oculofaciocardiodental (OFCD) syndrome and a novel BCOR pathogenic variant. Int Ophthalmol 2018;38:2677-82.

55. Gorlin RJ, Marashi AH, Obwegeser HL. Oculo-faciocardio-dental (OFCD) syndrome. Am J Med Genet 1996;63:290-2.

56. Ragge N, Isidor B, Bitoun $\mathrm{P}$, et al. Expanding the phenotype of the $\mathrm{X}$-linked BCOR microphthalmia syndromes. Hum Genet 2019;138:1051-69.

57. Al-Dosari MS, Almazyad M, Al-Ebdi L, et al. Ocular manifestations of branchio-oculo-facial syndrome: report of a novel mutation and review of the literature. Mol Vis 2010;16:813-8.

58. Bökenkamp A, Ludwig M. The oculocerebrorenal syndrome of Lowe: an update. Pediatr Nephrol 2016;31:2201-12. 